\title{
AGV Brake System Simulation
}

\author{
Daniel Varecha ${ }^{1}$, Robert Kohar ${ }^{1}$ and Frantisek Brumercik ${ }^{1 *}$ \\ ${ }^{1}$ University of Zilina, Faculty of Mechanical Engineering, Department of Design and Mechanical \\ Elements, Univerzitna 8215/1 01026 Zilina, Slovak Republic; Email: \\ daniel.varecha@fstroj.uniza.sk,robert.kohar@fstroj.uniza.sk,frantisek.brumercik@fstroj.uniza.sk
}

\section{*Corresponding Author: Frantisek Brumercik}

\begin{abstract}
The article is focused on braking simulation of automated guided vehicle (AGV). The brake system is used with a disc brake and with hydraulic control. In the first step, the formula necessary for braking force at the start of braking is derived. The stopping distance is 1.5 meters. Subsequently, a mathematical model of braking is created into which the formula of the necessary braking force is applied. The mathematical model represents a motion equation that is solved in the software Matlab by an approximation method. Next a simulation is created using Matlab software and the data of simulation are displayed in the graph. The transport speed of the vehicle is 1 $\left[\mathrm{m} . \mathrm{s} \rrbracket^{\wedge}(-1)\right.$ and the weight of the vehicle is $6000 \mathrm{~kg}$ including load. The aim of this article is to determine the braking time of the device depending from the input data entered, which represent the initial conditions of the braking process.
\end{abstract}

Keywords: Brake system, automatic guided vehicle, braking disk, braking simulation, safety

\section{Introduction}

The contribution is focused on design brake system with brake disk for automated guided vehicle (AGV) with the aim to reduce kinetic energy safety. The aim of this paper is to simulate the braking of the transport equipment commonly used in automotive logistic systems using a disc brake. The simulation is performed at chosen version of such device. The design of the braking system will depend on the simulation. The proposed brake disc will be applicable to an existing AGV device. It should be remembered that the size of the braking system will depend on the transport speed and the weight of the cargo being transported $[1,2]$.

\section{The Mathematical Code for Model and Elements of the Mechanism}

The disc brake will serve for reducing the kinetic movement energy of the device. This version of the braking system is used in each modern transport device. It is a braking system, which is hydraulically controlled. Due to the size and number of parts of the conveyor device, only the device brake mechanism is created in the CAD environment of the Creo Parametric 4.0. (see Fig.1). 
The device (AGV) (see Fig.1) consists of an electric motor, gearbox and a wheel with a disc brake. The AGV device keeps driving at maximum speed $v=1 \mathrm{~m} \cdot \mathrm{s}^{-1}$. The weight of the device is $6000 \mathrm{~kg}$, include cargo. The braking distance is set at 1.5 meters. In the first step, it is very important to calculate the braking force. The calculated braking force will be needed for further calculations $[3,4]$. Calculating parameters will be expressed graphically. The best way to get the needed data is to create a simulation of braking in the Matlab software. Based on the output data from Matlab, the brake system for the device is designed $[5,6]$.

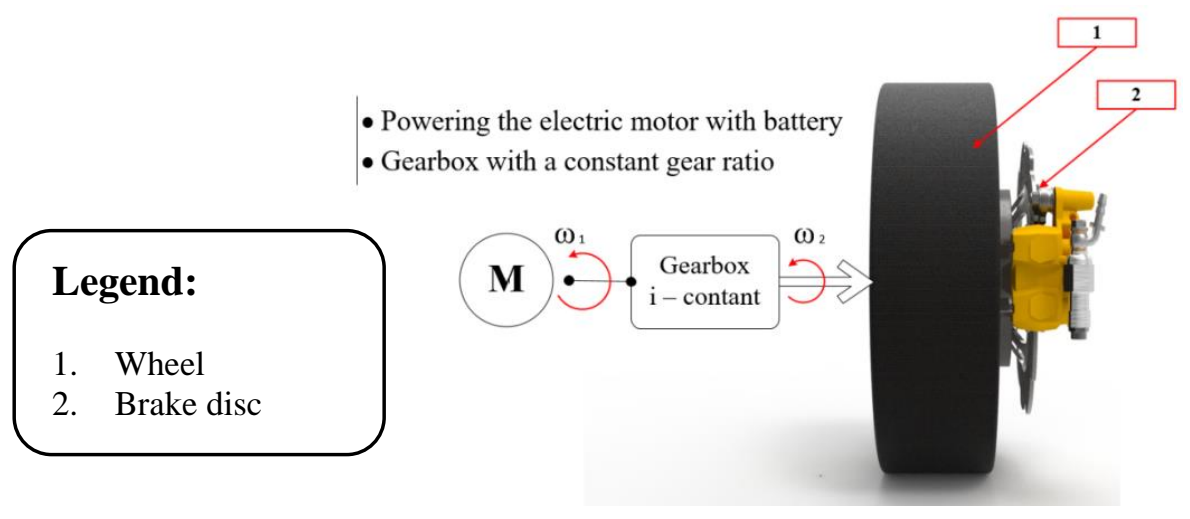

Fig. 1 Braking mechanism device. Source: authors

In Figure 2 is the mechanical assembly of the device, which is schematically illustrated with respective relationships.

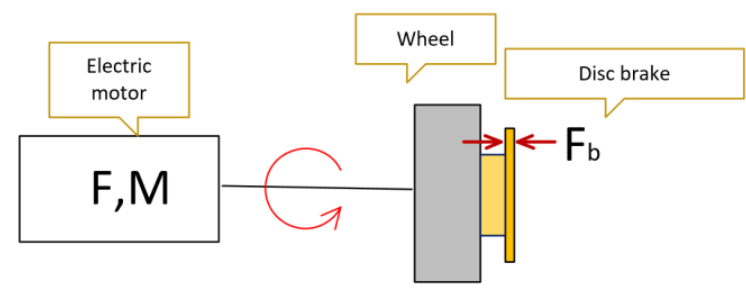

Fig. 2 Schematic representation of the device. Source: authors

Figure 3 illustrates the all forces acting on the device. The following rows will list all the equations needed to solve the task.

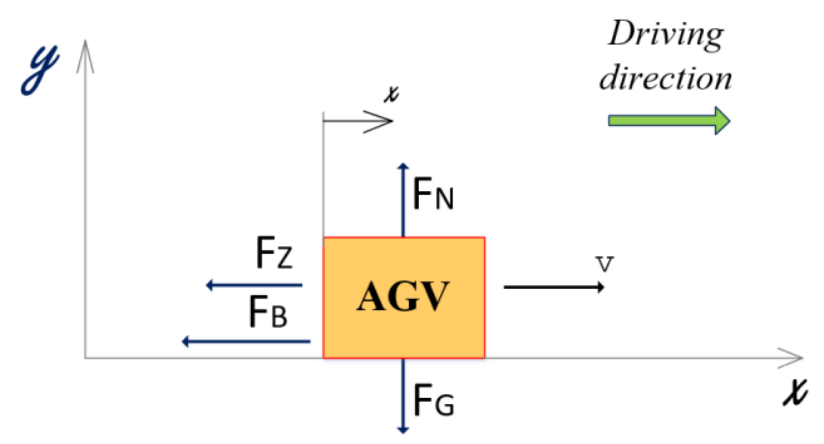

Fig. 3 Analysis of the forces. Source: authors 
At the beginning it is necessary to express the motion equation according to Figure 3 . Equation (see Eq. (1)) is the sum of all the forces acting on the vehicle [7,8]. In this case, wheel friction with the floor will not be considered. The device will not overcome the cant, it works on an ideal flat surface. The force $\overrightarrow{F_{G}}$, and $\overrightarrow{F_{N}}$ are perpendicular to the braking force $\overrightarrow{F_{B}}$, both equally large and opposite, and their result is zero. The acceleration in the y-axis direction is also zero [9].

\section{Motion equation in vector shape}

$$
\overrightarrow{F_{N}}-\overrightarrow{F_{B}}-\overrightarrow{F_{G}}=\overrightarrow{F_{Z}}, \quad[N]
$$

where: $F_{B}$ is braking force $[\mathrm{N}] ; F_{N}$ is normal force $[\mathrm{N}] ; F_{G}$ is gravitational force $[\mathrm{N}] ; F_{Z}$ is Inertia resistance of the vehicle [N] [1].

Subsequently, equation (see Eq. 1) is rewritten into a scalar shape (see Eq. (2) and (3))

$$
\begin{gathered}
x:-F_{B}=m \cdot \vec{a}, \quad[N] \\
y: F_{N}-F_{G}=0, \quad[N]
\end{gathered}
$$

where: $m$ is load $[\mathrm{kg}] ; \vec{a}$ is vector of acceleration $\left[\mathrm{m} . \mathrm{s}^{-2}\right], x$ is x coordinate; $y$ is y coordinate.

\section{Calculation of AGV acceleration (respectively slowing down)}

The relationship (see Eq. (2)) is overwritten to express an acceleration relationship (see Eq. (4)). The negative sign means slowing the device.

$$
a=-\frac{F_{B}}{m}, \quad\left[m \cdot s^{-2}\right]
$$

where: $a$ is acceleration $\left[m \cdot s^{-2}\right]$.

\section{Speed course $v(t)$}

Integrating acceleration from relationship (see Eq. (4)) expresses the speed - to - time dependence.

$$
v(t)=\int a d t=\int-\frac{F_{B}}{m} d t=-\frac{F_{B}}{m} \cdot t+c_{1}, \quad\left[m \cdot s^{-1}\right]
$$

where: $c_{1}$ is constant that is determined from the initial conditions; $t$ is time $[\mathrm{s}] ; v(t)$ is speed in time (t) $\left[m . s^{-2}\right]$. 
In the next step, equation (5) is overwritten into the following form (6)

$$
v(t)=-\frac{F_{B}}{m} \cdot t+v_{0},\left[m \cdot s^{-1}\right]
$$

where: $\mathrm{v}_{0}$ is the speed of the previous step $\left[\mathrm{m} . \mathrm{s}^{-1}\right]$.

\section{Route progress $(x)$ in time $(t)$}

By integrating the speed from relationship (see Eq. (6)) is the dependence of the path from time:

$$
x(t)=\int v(t) d t=\int\left(-\frac{F_{B}}{m} \cdot t+v_{0}\right) d t=-\frac{F_{B}}{m} \cdot t^{2}+v_{0} \cdot t+c_{2}, \quad[m]
$$

where: $c_{2}$ is constant that is determined from the initial conditions; $x(t)$ is the dependence of route on time $[m]$.

Equation (see Eq. (7)) is rewritten into the following form (see Eq. (8))

$$
x(t)=-\frac{F_{B}}{2 \cdot m} \cdot t^{2}+v_{0} \cdot t+x_{0}, \quad[m]
$$

where: $x_{0}$ is the route of the previous step $[m]$.

\section{Stop time $\left(t_{z}\right)$}

At the moment of stopping, the speed will be zero. Putting into a relationship (see Eq. (6)) for the stop time follows:

$$
0=-\frac{F_{B}}{m} \cdot t_{Z}+v_{0} \rightarrow t_{Z}=\frac{m \cdot v_{0}}{F_{B}}=\frac{6000 \mathrm{~kg} \cdot 1 \mathrm{~m} \cdot \mathrm{s}^{-1}}{2666,7 \mathrm{~N}}=2,25[\mathrm{~s}]
$$

where: $t_{z}$ is stop time $[s]$.

\section{Kinetic equation for AGV}

$$
E_{k}=\frac{1}{2} \cdot m \cdot v^{2}=\frac{1}{2} \cdot 6000 \mathrm{~kg} \cdot\left(1 \cdot \mathrm{m} \cdot \mathrm{s}^{-1}\right)^{2}=3000[\mathrm{~J}]
$$

where: $\mathrm{E}_{\mathrm{k}}$ is kinetic energy $[J]$.

Braking force needed to stop the device

$$
\begin{gathered}
\frac{1}{2} \cdot m \cdot v_{0}^{2}=\int_{0}^{s_{0}} F_{x} d x \\
F_{x}=F_{0} \cdot\left(1-\frac{x}{2 \cdot s_{0}}\right), \quad[N]
\end{gathered}
$$


where: $F_{x}$ is function; $s_{0}$ is braking distance $[m] ; F_{0}$ is braking force at the start of braking $[N]$.

Before the braking force is calculated at the beginning of the braking (see Eq. (17)), it is necessary to calculate the integral of the function $F_{x}$ (see Eq. (13)). After calculating (see Eq. (14)), the result is insert to the above equation (see Eq. (12)). Integral (see Eq. (14)) is calculated when considering braking route $s_{0}=1.5$ meters.

$$
\int_{0}^{s_{0}} F_{x} d x \rightarrow \text { the result is }=\frac{3}{4} \cdot F_{0} \cdot s_{0}, \quad[N]
$$

Subsequently, the brake force at the start of the brake (see Eq. (16)) is expressed from the equation (see Eq. (15)). In the last step, the required braking force is calculated based on the entered parameters.

$$
\begin{gathered}
\frac{1}{2} \cdot m \cdot v_{0}^{2}=\frac{3}{4} \cdot F_{0} \cdot s_{0} \rightarrow F_{0} \\
F_{0}=\frac{3}{4 \cdot s_{0}} \cdot\left(\frac{1}{2} \cdot m \cdot v_{0}^{2}\right) \\
F_{0}=\frac{2 \cdot m \cdot v_{0}^{2}}{3 \cdot s_{0}}=\frac{2.6000 \mathrm{~kg} \cdot\left(1 \cdot \mathrm{m} \cdot \mathrm{s}^{-1}\right)^{2}}{3 \cdot(1.5 \mathrm{~m})}=2666.7 \mathrm{~N} \rightarrow 2.67[\mathrm{kN}]
\end{gathered}
$$

The braking force of $2.67 \mathrm{kN}$ is required to stop the automated guided vehicle at a speed of 1. $m . \mathrm{s}^{-1}$ and $6000 \mathrm{~kg}$ (including cargo). The device will be equipped with two disc brakes. The braking force is divided between the two drive wheels. Below is a calculation of the braking torque (see Eq. (18)).

\section{Calculation of braking torque}

$$
M_{B}=F_{B} \cdot f \cdot r=2666,7 N \cdot 0,62 \cdot 0,26 m=429.9[\mathrm{Nm}]
$$

where: $M_{B}$ is braking torque $[N m], f$ is coefficient of kinetic friction [-], $r$ is radius of brake disk $[m]$.

Figure 4 schematically shows the braking force, braking torque as well as the radius of the braking disk.

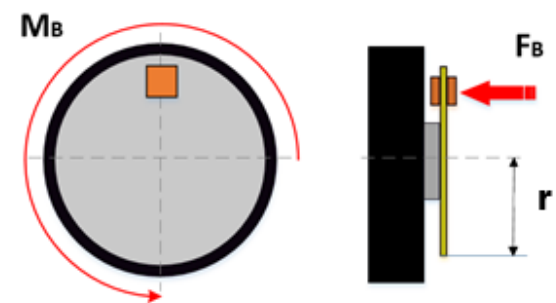

Fig. 4 Graphic representation of the forces acting on the disc brake system. Source: authors 


\section{Results}

It is clear from the graph (see Fig. 5) that the speed is decreased to the point where the conveying device stops completely $\left(v=0 \mathrm{~m} . \mathrm{s}^{-1}\right)$. The route is increased during the braking simulation, which indicates that the Matlab program is set correctly. When it comes to accelerating the device (respective slowing down) from the graph, it is clear that the device is slowing down to the point where it stops.

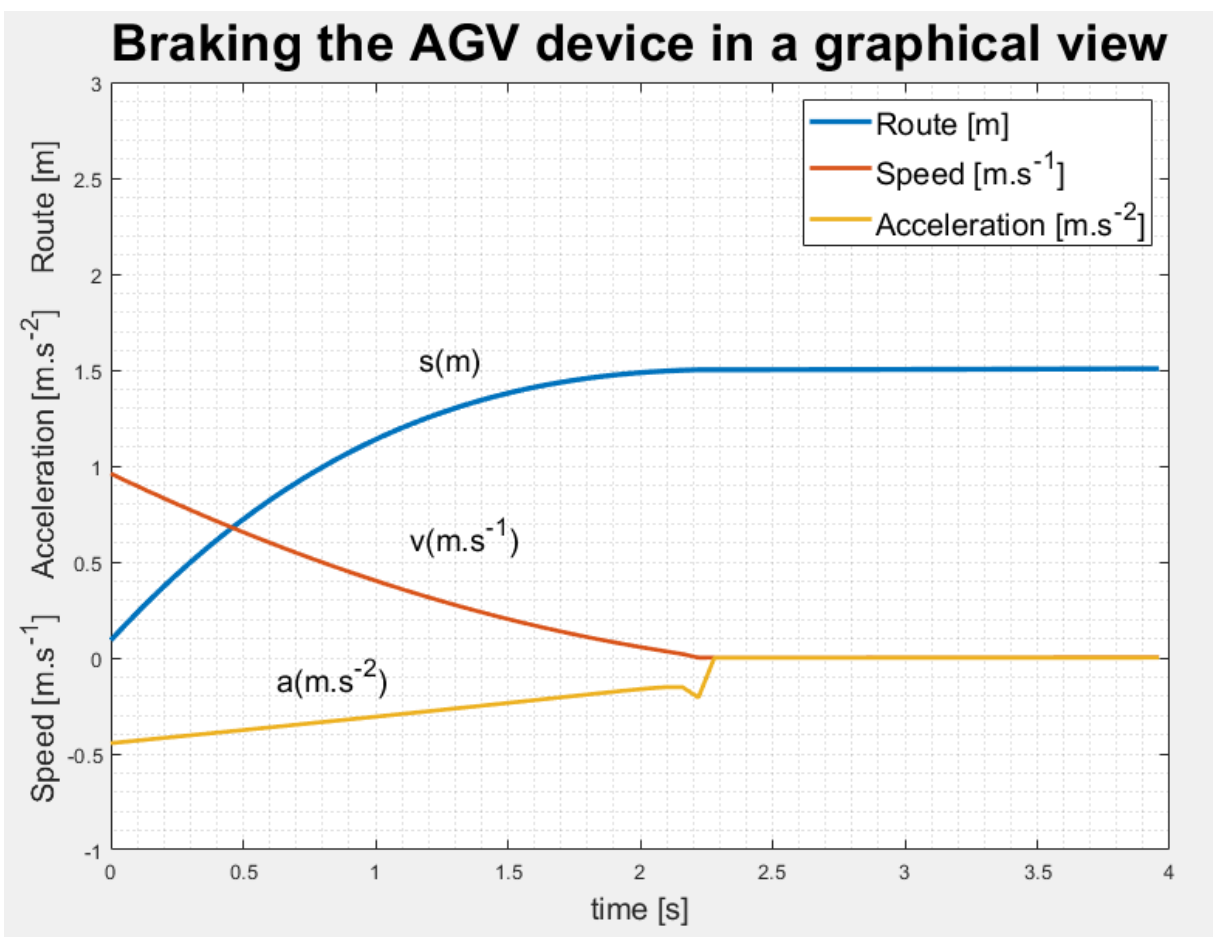

Fig. 5 Braking AGV at selected parameters. Source: authors

According to the calculations in Chapter 2, the device will reduce its kinetic energy to zero in 2.25 seconds and pass a distance of 1.5 meters. "The calculated data was verified by simulation in the Matlab computing environment. Figure 6 shows detail from graph that represents the complete stop of AGV. Simulation matches with the mathematical calculation.

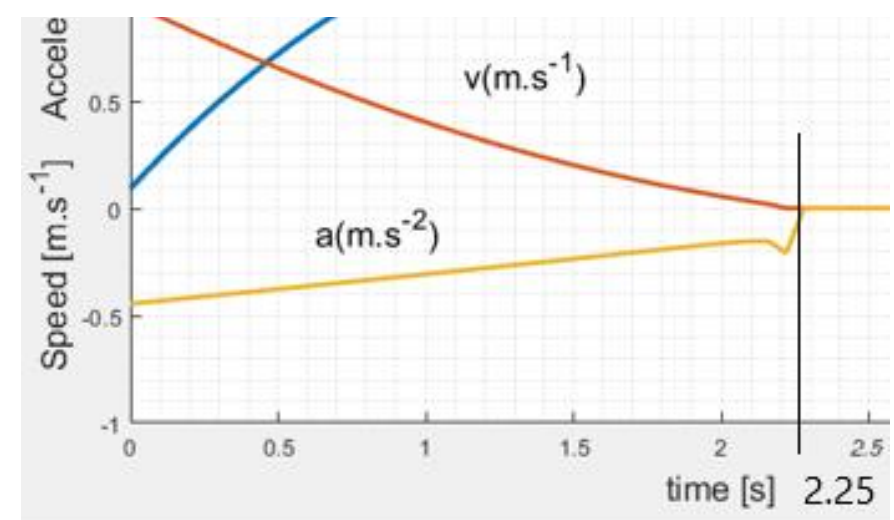

Fig. 6 Time braking - detail. Source: authors 
Figure 7 shows the braking torque during braking. As you can see by decreasing the speed, the brake torque also decreases.

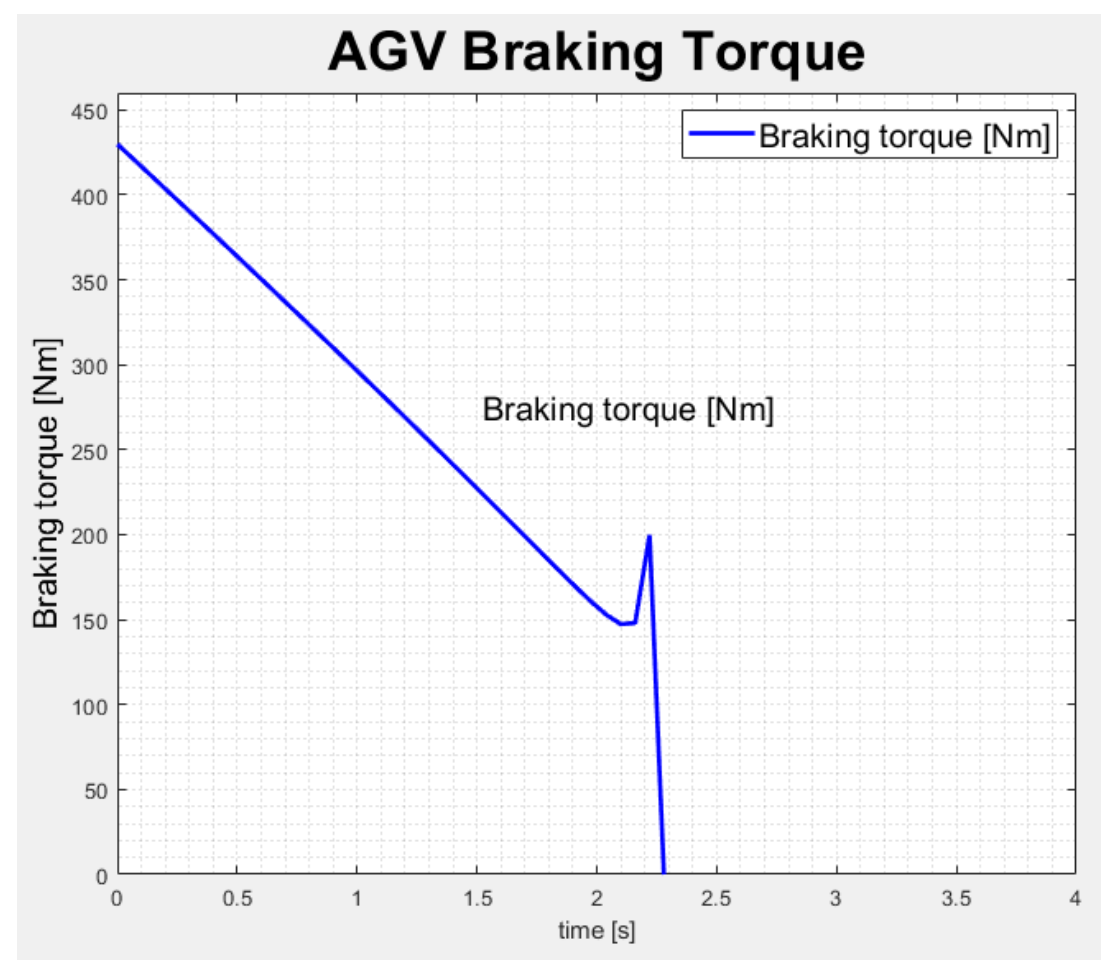

Fig. 7 AGV - Brake torque. Source: authors

\section{Discussion}

Due to the fact, that braking force is large, there are several operational and technical problems in the design of the braking system $[10,11]$. As the disc brake operation is secured by hydraulic force, energy is needed to brake from the batteries. Ultimately, this reduces the range.

- How to operate the transport equipment economically?

- Is it necessary to equip the brake for the other two wheels except for the drive axle in the view of the high braking power?

The market offers more power versions of the device and therefore it is necessary to consider the modular braking system $[12,13]$.

\section{Conclusion}

The aim of the paper was to describe the mathematical model [14] of the braking of the automated guided vehicle in the computing environment of the Matlab software. The parameters that are based on real traffic (speed, load) were selected for the calculation $[15,16]$. The device used to analyze reached the maximum speed $v=1 \mathrm{~m} \cdot \mathrm{s}^{-1}$ with a transported weight of $6000 \mathrm{~kg}$. The stopping distance was set to 1.5 meters and the required braking force $(2.67 \mathrm{kN})$ was then calculated to stop the device. Outputs from the Matlab computational software are presented graphically and express 
the reduction of speed, deceleration and path. The calculation also examined the value of the braking torque $(429.9 \mathrm{Nm})$ required for the correct design of the brake caliper. The objectives that were set have fully met.

\section{Acknowledgments}

The research is supported by the Cultural and Educational Grant Agency of the Ministry of Education, Science, Research and Sport of the Slovak Republic under the project No. 046ŽU$4 / 2018$.

\section{References}

[1] Filo, M. \& Lukáč, M. (2005). Modeling and Simulation of Mechanisms with Computer Support. Žilina: EDIS.

[2] Rievaj, V., Šulgan, M. \& Hudák, A. (2013). Car and its Dynamics. Žilina: EDIS.

[3] Czech, P. (2017). Physically Disabled Pedestrians - Road Users in Terms of Road Accidents. Contemporary Challenges of Transport Systems and Traffic Engineering, edited by Elzbieta Macioszek, Grzegorz Sierpinski, 157-165. Switzerland: Springer International Publishing.

[4] Czech, P. (2017). Underage Pedestrian Road Users in Terms of Road Accidents. Intelligent Transport Systems and Travel Behaviors, edited by Grzegorz Sierpinski, 33-44. Switzerland: Springer International Publishing.

[5] Glowacz, A. \& Glowacz, Z. (2017). Diagnosis of the three-phase induction motor using thermal imaging. Infrared physics \& technology 81: 7-16. DOI: 10.1016/j.infrared.2016.12.003.

[6] Czech, P. (2017). Underage Pedestrian Road Users in Terms of Road Accidents. Intelligent Transport Systems and Travel Behaviors, edited by Grzegorz Sierpinski, 33-44. Switzerland: Springer International Publishing.

[7] Figlus T. \& Koziol M. (2016). Diagnosis of early-stage damage to polymer - glass fibre composites using non-contact measurement of vibration signals. Journal of Mechanical Science and Technology. 30(8), 3567-3576. DOI: 10.1007/s12206-016-0717-1.

[8] Skrucany T., Sarkan B., Figlus T., Synák, F. \& Vrábel, J. (2017). Measuring of noise emitted by moving vehicles. MATEC Web of Conferences, 107:00072.

[9] Nieoczym A. (2005). Application of a transportation flux for determining qualitative indices. Communications - Scientific Letters of the University of Žilina. 7(1), 47-48. 
[10] Koziol, M. \& Figlus, T. (2017). Evaluation of the Failure Progress in the Static Bending of GFRP Laminates Reinforced With a Classic Plain-Woven Fabric and a 3D Fabric, by Means of the Vibrations Analysis. Polymer Composites. 38 (6), 1070-1085.

[11] Drozdziel, P., Brumercikova, E. \& Bukova, B. (2015). The Use of Progressive Methods of Serving Passengers. Transport problems. 10(4).

[12] Drozdziel, P., \& Krzywonos. L. (2009). The Estimation of the Reliability of the First Daily Diesel Engine Start-up during its Operation in the Vehicle. Eksploatacja i Niezawodnosc Maintenance and Reliability. 1(41), 4-10.

[13] Caban, J., Drozdziel, P., Vrabel, J., Sarkan, B., Marczuk, A., Krzywonos, L., \& Rybicka, I. (2016). The research on ageing of glycol-based brake fluids of vehicles in operation. Advances in Science and Technology. 10(32), 9-16.

[14] Caban, J., Marczuk, A., Sarkan, B. \& Vrabel, J. (2015). Studies on operational wear of glycolbased brake fluid. Przemysł Chemiczny. 94(10), 1802-1806.

[15] Stopka, O., Kampf, R. \& Vrabel, J. (2016). Deploying the Means of Transport within the Transport Enterprises in the Context of Emission Standards, In: 20th International Scientific Conference on Transport, 05-07 October 2016 (pp. 185-190).

[16] Stopka, O. \& Kampf, R. (2018). Determining the most suitable layout of space for the loading unit's handling in the maritime port. Transport. 33(1), 280-290. DOI: https://doi.org/10.3846/16484142.2016.1174882. 